\title{
Pelatihan Pengolahan Dodol Susu Labu Kuning (Dollabu) sebagai upaya Meningkatkan Nilai Jual dan Kreasi Olahan Labu Kuning di Kelurahan Toriki Kecamatan Anggaberi
}

\author{
Milawati Saranani ${ }^{1}$, dan Hasniati ${ }^{2}$ \\ Program Studi Agribisnis Fakultas Pertanian \\ Universitas Lakidende \\ Email: milasaranani76@gmail.com \\ atihasniati@gmail.com
}

\begin{abstract}
ABSTRAK
Kegiatan ini dilaksanakan di Kelurahan Toriki Kecamatan Anggaberi Kabupaten Konawe. Para peserta yang mengikuti kegiatan ini adalah ibu-ibu anggota KWT (Kelompok Wanita Tani) yang tergabung dalam kelompkok usaha "Mesida" dengan jumlah peserta sebanyak 15 orang. Para peserta aktif dalam mengikuti kegiatan ini baik pada saat ceramah, diskusi maupun saat pembuatan produk. Untuk mencapai tujuan pengabdian kepada masyarakat ini dilaksanakan metode sosialisasi, pelatihan dan praktik.

Peran aktif masyarakat ini disebabkan karena masyarakat kelurahan Toriki sangat memerlukan informasi terkait dengan penerapan teknologi dalam pengolahan labu kuning menjadi dodol susu labu kuning (Dollabu). Tanggapan masyarakat kelurahan Toriki selaku peserta pelatihan sangat positif. Keberhasilan pelaksanaan seluruh kegiatan pengabdian kepada masyarakat ini tentunya mempunyai manfaat yang cukup baik bagi masyarakat pada umumnya dan pelaku industri rumah tangga khususnya. Adanya peningkatan pengetahuan masyarakat tentang pengolahan dodol susu labu kuning (Dollabu), masyarakat dapat melakukan pengolahan sendiri sehingga dapat meningkatkan pendapatan dan kesejahteraan masyarakat.
\end{abstract}

Kata Kunci : pelatihan, dan dodol susu labu kuning

\begin{abstract}
This activity was carried out in Toriki Village, Anggaberi District, Konawe Regency. The participants who took part in this activity were women members of the KWT (Women's Farmers Group) who are members of the "Mesida" business group with a total of 15 participants. The participants are active in participating in this activity both during lectures, discussions and during product making. To achieve this goal of community service, socialization methods, training and practice are carried out.

The active role of the community is due to the fact that the people of Toriki village really need information related to the application of technology in processing yellow pumpkin into pumpkin milk lunkhead (Dollabu). The response of the people of Toriki Village as training participants was very positive. The successful implementation of all these community service activities certainly has quite good
\end{abstract}


benefits for the community in general and for household industry players in particular. With an increase in public knowledge about the processing of pumpkin milk lunkhead (Dollabu), people can do the processing themselves so that they can increase their income and welfare.

Keywords: training, and yellow pumpkin dodol milk

\section{PENDAHULUAN}

Buah-buahan umumya merupakan bahan pangan sumber vitamin $\mathrm{C}$ seperti halnya dengan buah dengen ( lebih $84 \%$ vitamin C). Buah-buahan mempunyai sifat yang sangat mudah rusak, dan ketika hal itu terjadi maka nilai gizi pada buah berkurang dan juga akan berdampak pada nilai harga jual dari buah tersebut. Kerusakan pada buah-buahan dapat berupa penanganan pasca panen yang kurang hati-hati maupun faktor internal lainnya (Nur Ilma, 2012).

Tanaman Labu kuning memiliki banyak manfaat bagi kesehatan diantaranya sebagai penambah nafsu makan anak, memperbaiki tekanan darah tinggi, gangguan kandung kemih, sakit maag, memperbaiki kulit kusam dan menghilangkan flek hitam. Selain itu, waluh juga mengandung antioksidan sebagai penangkal radikal bebas dan kanker Sifat labu kuning yang lunak dan mudah dicerna serta mengandung karoten (pro vitamin A) cukup tinggi, serta dapat menambah menarik warna pangan (Yoko, 2012).

Labu kuning atau waluh termasuk komoditas pangan yang pemanfaatannya masih sangat terbatas. Hal ini disebabkan karena masyarakat masih belum menyadari potensi dan kandungan gizi labu kuning. Penyebaran buah labu kuning cukup merata di Indonesia, hampir semua kepulauan di Indonesia dijumpai tanaman labu kuning (Gardjito,2006).

Labu kuning telah dimanfaatkan menjadi produk-produk industri yang potensial, misalnya dalam bidang kesehatan, diantaranya sebagai obat penurun panas, obat demam, obat menurunkan tekanan darah dan lain-lain (Kanisius, 2005). Manfaat labu kuning untuk pengobatan antara lain penyembuhan radang, pengobatan ginjal, pengobatan demam dan pengobatan diare (Emma S. Wirakusumah, 2003).

Labu kuning merupakan buah yang masih jarang dimanfaatkan oleh industri pangan. Labu kuning memiliki daya simpan yang cukup lama, namun volumenya besar dan mudah rusak dalam pengangkutan, sehingga perlu diolah 
menjadi produk yang lebih tahan lama dan bernilai ekonomis. Labu kuning dapat diolah menjadi kudapan seperti dodol, kolak, roti, bolu, dan sebagainya. Salah satu bentuk pengolahan labu kuning untuk meningkatkan nilai tambahnya yaitu dengan mengolah labu kuning menjadi dodol (Dollabu) dan bola-bola labu kuning (Bollaku) dengan varian isi cokelat dan keju dengan teknologi yang sederhana, mudah dan terjangkau.

Dodol merupakan salah satu makanan tradisional yang mudah dijumpai di beberapa daerah di Indonesia. Dodol memiliki rasa manis gurih, berwarna cokelat, tekstur lunak, digolongkan makanan semi basah (Prayitno, 2002).

Dodol merupakan makanan tradisional yang cukup popular yang sudah dikenal sejak zaman dahulu yang diolah dengan cara tradisional. Saat ini dodol lebih dikenal dengan nama daerah asalnya seperti dodol Garut, dodol Kudus atau jenang Kudus, gelamai dari Sumatra Barat, dodol durian atau lempog dari Sumatra dan Kalimatan. Dodol termasuk produk olahan setengah basah yang padat dan kenyal, produk sejenis yang dibuat secara tradisional disebut jenang dengan tekstur lebih lembek dan berminyak (Suprapti, 2005).

Di pasaran telah beredar berbagai macam dodol yang telah diinovasi, diantaranya dodol buah. Bahan pembuat dodol buah bermacam-macam, ada yang terbuat dari buah dan gula, serta ada pula yang dibuat dari tepung, buah, gula dan santan. Hampir semua jenis buah dapat diolah menjadi dodol. Dodol buah yang dihasilkan tergantung jenis buah yang digunakan, seperti dodol nangka, dodol mangga, dodol biji mangga, dodol apel, dodol durian, dan masih banyak lagi. Fungsi dari pengolahan buah-buahan menjadi dodol yaitu dapat memperpanjang daya simpan buah. Buah yang akan diolah menjadi dodol harus matang penuh, seragam tingkat kematangannya dan tidak busuk (Fatma, 2015).

Dodol susu labu kuning (dollabu) menjadi alternatif baru sebagai olahan makanan yang aman dan menyehatkan, karena dodol labu kuning tidak mengandung bahan tambahan makanan yang berbahaya. Jadi selain tampilannya cantik dan banyak khasiat dodol labu kuning (Dollabu) sangat aman dikonsumsi oleh segala golongan dan lapisan masyarakat.

Keluruhan Toriki Kecamatan Anggaberi Kabupaten Konawe merupakan salah satu wilayah yang memiliki beragam potensi lokal dan masyarakatnya pada 
umumnya adalah petani. Salah satu komoditas yang diusahakan adalah labu. Labu kuning ini kebanyakan tidak diolah oleh masyarakat, melainkan dijual mentah sebagai olahan untuk sayur yang dijual dipasar tradisional. Labu kuning yang sudah matang dan besar dengan harga rata-rata Rp. 10.000 - Rp. 15.000 perbuah. Kegiatan pengabdian kepada masyarakat ini dalam rangka mengaplikasikan Iptek berbasis pengolahan hasil pertanian. Tujuan kegiatan ini adalah pemberdayaan masyarakat melalui pengolahan dodol susu labu kuning (Dollabu) sebagai upaya meningkatkan pendapatan rumah tangga.

\section{METODE PENELITIAN}

Kegiatan ini dilaksanakan di Kelurahan Toriki Kecamatan Anggaberi Kabupaten Konawe. Pelatihan ini diikuti oleh kelompok wanita tani "Mesida" yang berangggotakan 15 orang. Untuk mencapai tujuan pengabdian kepada masyarakat ini dilaksanakan metode sosialisasi, pelatihan dan praktik. Kegiatan pertama diawali dengan sosialisasi kepada ibu-ibu kelompok wanita tani yang tergabung dalam kelompok usaha "Mesida" tentang pelatihan dan praktik pengolahan dodol susu labu kuning yang berbahan dasar labu kuning. Bahan utama tersebut dipilih karena mudah didapat di Kelurahan Toriki Kecamatan Anggaberi.

Pelaksanaan praktik pengolahan labu kuning menjadi dodol susu labu kuning, lebih tepatnya dilakukan di balai keluruhan Toriki. Pelaksanaan pelatihan dan praktik pengolahan dodol susu labu kuning yang dihadiri oleh lurah kelurahan Toriki dan tim dari LPPM Unilaki. Dan pada pelaksanaan pelatihan, peserta pelatihan mendengarkan presentasi terkait manfaat labu kuning, komposisi dan resep dari dodol susu labu kuning yang dibuat dalam kegiatan pelatihan pengabdian kepada masyarakat. Tim pengabdian kepada masyarakat sebagi pemateri menyampaikan materi-materi yang terkait dengan metode memasak, bentuk display makanan, dan tentunya membahas bahan utama yang digunakan, yakni labu kuning. Pelaksanaan kegiatan pelatihan masak ini berlangsung pada bulan Agustus 2020 dengan durasi selama 3 jam, yakni mulai jam 09.00-12.00 WITA. 


\section{HASIL DAN PEMBAHASAN}

Kelurahan Toriki adalah salah satu kelurahan yang ada di Kecamatan Anggaberi Kabupaten Konawe yang banyak membudidayakan komoditas labu kuning. Biasanya labu kuning hanya dikonsumsi sebagai sayuran, padahal labu kuning dapat di diversfisikasi menjadi olahan kue (cake) dan kreasi panganan lainnya yang bercita rasa lokal tapi dengan tampilan yang kekinian/modern yang tentunya bernilai gizi tinggi karena menggunakan olahan komoditas pangan lokal. Produk olahan labu kuning sangat berpotensi untuk dikembangkan menggunakan teknologi yang telah ada sehingga diharapkan kedepannya dapat meningkatkan pendapatan rumah tangga khususnya petani.

Target khusus dari kegiatan pelatihan ini, bahan baku diubah menjadi barang jadi dalam skala besar dan diminati oleh masyarakat, sebagai salah satu produk unggulan labu kuning. Produksi hasil olahan berupa Dollabu (dodol susu labu kuning) akan dijadikan salah satu makanan dengan cita rasa khas pangan lokal dari Konawe. Selain dodol susu labu kuning (Dollabu) labu kuning juga masih dapat di diversifikasi menjadi olahan cookies dan bread serta pie susu labu kuning.

Labu kuning di kebanyakan wilayah Desa atau Kelurahan di Kabupaten Konawe hanya diolah menjadi sayuran baik labu yang masih kecil (berwarna hijau) maupun yang sudah matang (berwarna Kuning), olahan selain sayur yaitu sebagai campuran untuk membuat donat dan kolak. Untuk itu, perlu ada inovasi di Kelurahan Toriki Kecamatan Anggaberi untuk mengkreasikan bahan utama labu kuning menjadi suatu makanan yang tampilannya unik, menarik, namun tetap lezat untuk dinikmati, khususnya bagi anak kecil dan remaja.. Karenanya dari pihak pengabdian masyarakat menginisiasi untuk melakukan suatu kegiatan untuk melestarikan dan mengkreasikan bahan makanan dari labu kuning, salah satunya menjadi dodol. Hal ini dilakukan sebagai salah satu cara untuk dapat membuktikan eksistensi labu kuning menjadi makanan tradisional namun juga dapat merambah ke makanan modern dan berkelas dengan tampilan yang menarik. 
Tujuan dari kegiatan pelatihan pengabdian kepada masyarakat ini adalah:

1. Menumbuhkan semangat berwirausaha bagi masyarakat khususnya wanita tani melalui pembentukan kelompok usaha bersama maupun mandiri..

2. Memberdayakan potensi masyarakat khususnya wanita tani dalam meningkatkan pendapatan keluarga melalui peningkatan usaha ekonomi produktif

Manfaat dari kegiatan pelatihan pengabdian kepada masyarakat ini adalah:

1. Memberi alternatif usaha pada masyarakat, sehingga dapat meningkatkan kesejahteraan keluarga.

2. Membekali masyarakat untuk memiliki jiwa kewirausahaan dalam mengembangkan usaha ekonomi produktif berbasis pangan lokal.

Khalayak sasaran yang strategis dalam kegiatan ini adalah masyarakat yang tergolong dalam kelompok wanita tani "Mesida" yang berada di Kelurahan Toriki Kecamatan Anggaberi. Jumlah peserta pelatihan sebanyak 15 orang terdiri wanita.

Dalam rangka mencapai tujuan yang tercantum di atas, maka ditempuh langkah-langkah sebagai berikut;

1. Menghubungi Lurah Toriki untuk mendiskusikan topik yang hendak diabdikan yaitu pelatihan pengolahan dodol susu labu kuning (Dollabu) sebagai upaya meningkatkan nilai jual dan kreasi olahan labu kuning di Kelurahan Toriki melalui pengolahan komoditas labu kuning menjadi dodol dan mencari data jumlah warga masyarakat yang tergolong kelompok wanita tani sebagai calon peserta pelatihan

2. Menyelenggarakan pelatihan, dengan materi:

a. Kewirausahaan

b. Menemukan Peluang Usaha berbasis pangan lokal (labu kuning)

c. Manajemen usaha

d. Peningkatan keterampilan, berupa pelatihan pembuatan produk yaitu dodol dan roti sobek ala labu kuning.

Kegiatan ini tidak akan mungkin berhasil tanpa adanya keterkaitan dengan beberapa pihak lain. Dalam hal ini pihak Kelurahan Toriki Kecamatan Anggaberi Kabupaten Konawe sebagai pihak yang mempunyai wilayah di mana kegiatan 
Pengabdian Pada Masyarakat hendak dilakukan, memberi dukungan dalam kegiatan ini dengan menyediakan tempat pelatihan. Diharapkan melalui program pengabdian kepada masyarakat ini dapat memberikan kontribusi usaha khususnya pada wanita tani melalui pembentukan Kelompok Usaha Bersama maupun mandiri.

Para peserta yang mengikuti kegiatan ini adalah ibu-ibu anggota KWT (Kelompok Wanita Tani) Mesida dengan jumlah peserta sebanyak 15 orang. Para peserta aktif dalam mengikuti kegiatan ini baik pada saat ceramah, diskusi maupun saat pembuatan produk. Peran aktif masyarakat ini disebabkan karena masyarakat kelurahan Toriki sangat memerlukan informasi terkait dengan penerapan teknologi dalam pengolahan labu kuning menjadi dodol susu labu kuning (Dollabu).

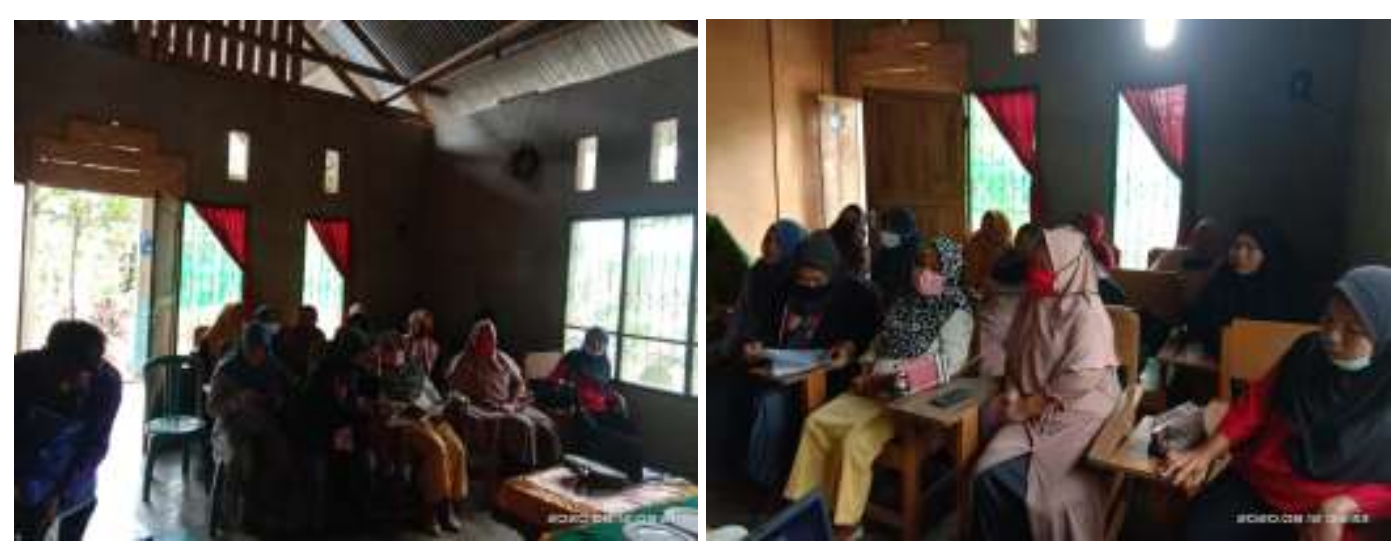

Gambar 1. Peserta Pelatihan Pengolahan Dodol Susu Labu Kuning (Dollabu)

Tanggapan masyarakat kelurahan Toriki selaku peserta pelatihan sangat positif. Peserta pelatihan sangat antusias dalam mengikuti kegiatan ini yang ditunjukan dari banyaknya ibu-ibu peserta yang mengajukan ikut serta dalam proses praktek/demontrasi produk olahan pada saat acara kegiatan berlangsung. Mereka juga praktek langsung mengikuti arahan instruktur pelatihan untuk mengolah langsung labu kuning hingga akhirnya menjadi produk berupa dodol susu labu kuning (Dollabu). 

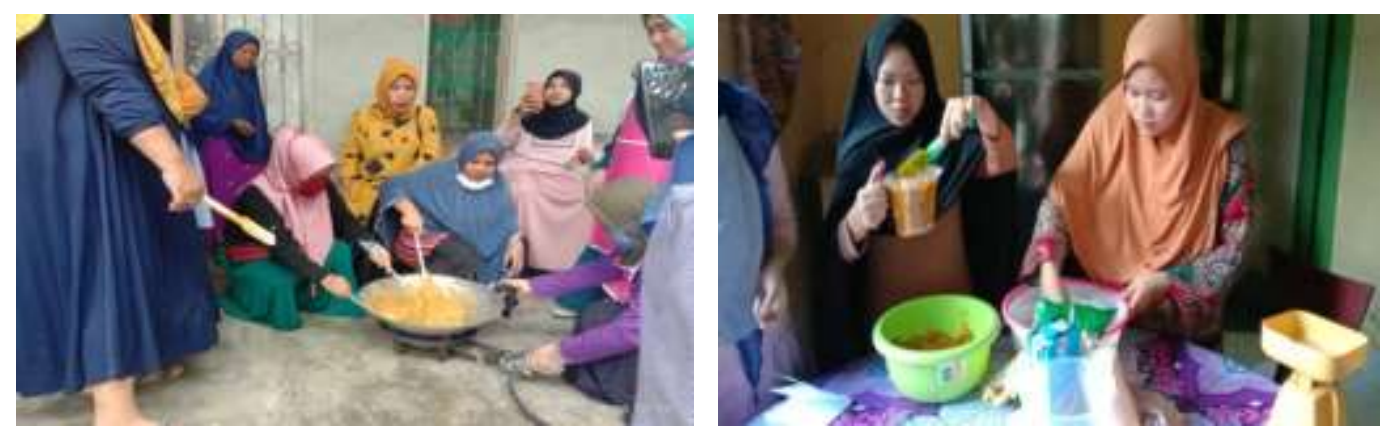

Gambar 2. Pengolahan Labu Kuning Menjadi Dodol Susu labu Kuning (Dollabu)

Masyarakat juga tertarik dengan teknologi pengolahan labu kuning menjadi dodol susu labu kuning (Dollabu) disebabkan karena cara pembuatannya mudah dan peralatan yang dipergunakan juga sederhana. Kualitas produk yang dihasilkan dari kegiatan ini dapat langsung dirasakan oleh masyarakat serta adanya keinginan untuk melakukan pengolahan sendiri maupun berkelompok.

Pengolahan dodol susu labu kuning tidak menggunakan bahan-bahan yang mengandung zat yang berbahaya dan zat pengawet. Bahan-bahan yang digunakan dalam pembuatan dodol susu labu kuning (Dollabu) yaitu $2 \mathrm{~kg}$ labu kuning, 500 gram tepung ketan putih 400 gram gula pasir 250 gram gula merah $150 \mathrm{ml}$ santal kental Secukupnya garam 200 gram tepung beras $250 \mathrm{ml}$ susu cair 1 bungkus agar-agar plain merk swallow. Adapun Cara Membuatnya adalah (1) Kupas labu kuning, kemudian potong ukuran agak kecil dan cuci bersih, tiriskan, setelah itu kukus hingga matang dan haluskan labu kuning seperti bubur, (2) Campur bubur labu kuning dengan tepung ketan putih dan tepung beras, aduk-aduk hingga rata, (3) Panaskan adonan dasar dodol sambil diaduk, (3) Sambil dipanaskan, masukkan agar-agar, susu cair, santan, gula pasir, gula merah dan garam, (4) Aduk-aduk terus hingga adonan berubah menjadi kental, agak kering dan kecolaktan, (5) Lalu tuangkan adonan kedalam wadah/cetakan, (6) Tunggu sampai benar-benar dingin dan kemas dodol menurut selera dengan kertas minyak/bungkus plastik. 

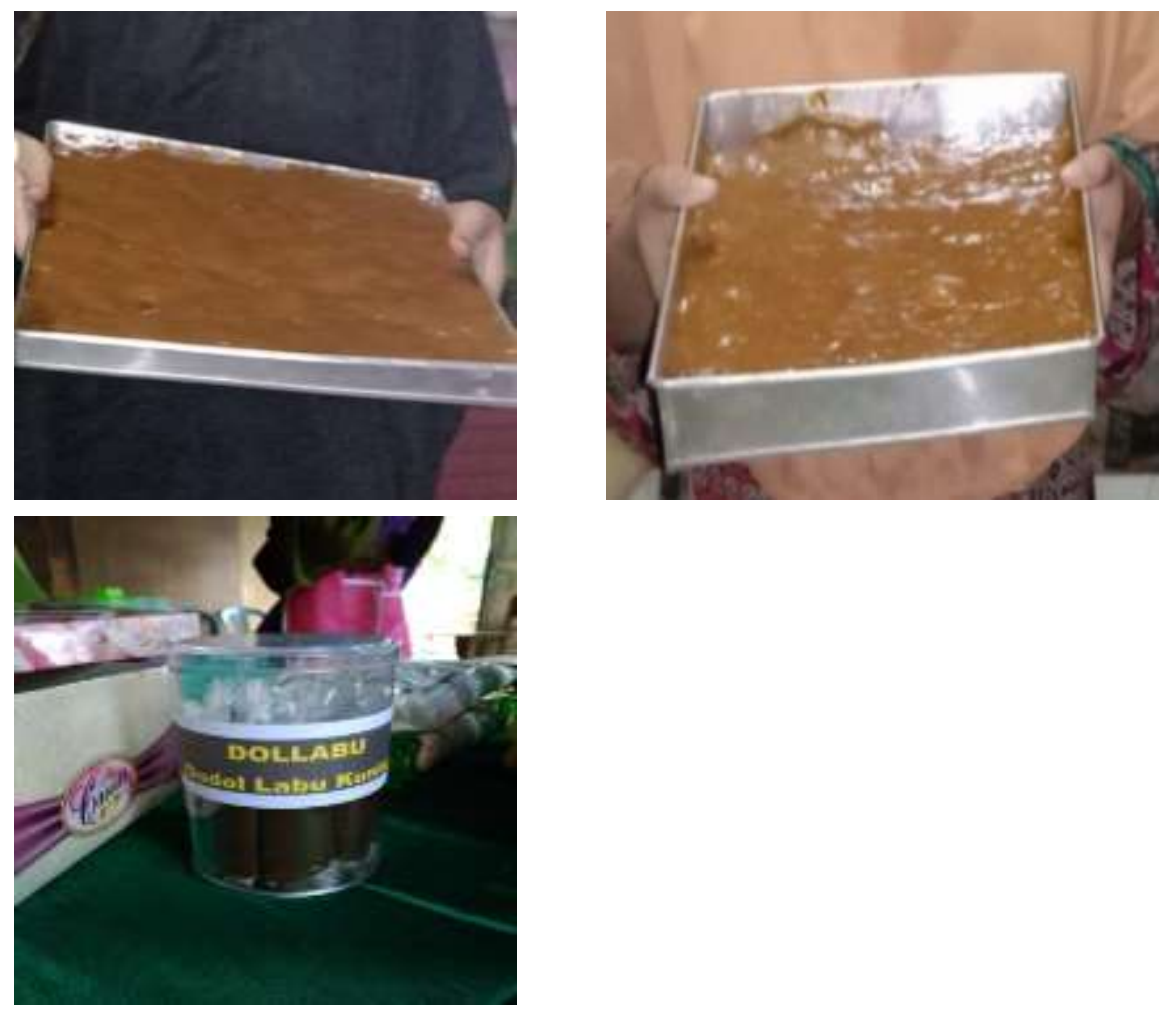

Gambar 3. Hasil Olahan Dodol Susu Labu Kuning yang Sudah Matang, dicetak, dan dikemas.

Keberhasilan pelaksanaan seluruh kegiatan pengabdian kepada masyarakat ini tentunya mempunyai manfaat yang cukup baik bagi masyarakat pada umumnya dan pelaku industri rumah tangga khususnya. Adanya peningkatan pengetahuan masyarakat tentang pengolahan dodol susu labu kuning (Dollabu), masyarakat dapat melakukan pengolahan sendiri sehingga dapat meningkatkan pendapatan dan kesejahteraan masyarakat.

\section{PENUTUP}

Peran aktif masyarakat ini disebabkan karena masyarakat kelurahan Toriki sangat memerlukan informasi terkait dengan penerapan teknologi dalam pengolahan labu kuning menjadi dodol susu labu kuning (Dollabu). Tanggapan masyarakat kelurahan Toriki selaku peserta pelatihan sangat positif. Keberhasilan pelaksanaan seluruh kegiatan pengabdian kepada masyarakat ini tentunya mempunyai manfaat yang cukup baik bagi masyarakat pada umumnya dan pelaku industri rumah tangga khususnya 


\section{DAFTAR PUSTAKA}

Emma S, Wirakusumah. 2003. Buah dan Sayur untuk Terapi. Jakarta : Penebar Swadaya

Fatma Mia Aulia. 2015. Eksperimen Pembuatan Dodol labu Kuning. Skripsi Jurusan Pendidikan Kesejahteraan Keluarga Fakultas Teknik Universitas Negeri Semarang

Gardjito, M. 2006. Labu Kuning Sumber Karbohidrat Kaya Vitamin A.Tridatu Visi Komunitas. Yogyakarta.

Kanisius. 2005. Aneka Olahan Belagu dan Labu. Yogyakarta : Kanisius.

Nur Ilma. 2012. Studi Pembuatan Dodol Buah Dengen (Dillenia serrata Thunb). Skripsi Program Studi Ilmu dan Teknologi Pangan Jurusan Teknologi Pertanian Fakultas Pertanian Universitas Hasanuddin Makassar.

Prayitno, S. (2002). Aneka Olahan Dodol. Yogyakarta : Kanisius.

Suprapti, L. 2005. Awetan Kering dan Dodol Waluh. Yogyakarta : Kanisius

Yoko. 2012. Labu. Media Komputindo, Jakarta. 